\title{
Morocco meteorite falls and finds: some statistics
}

\author{
Abderrahmane Ibhi \\ Geoheritage and Geomaterials Laboratory, Faculty of Sciences, University of Ibn Zohr, \\ B.P. 8106, Agadir, Morocco \\ E-mail address: a.ibhi@uiz.ac.ma
}

\begin{abstract}
Since the first recorded discovery of a meteorite in 1937 near the Mrirt village (Khenifra, Morocco), a total of 946 authenticated meteorites have been recorded in Morocco. The material, including 10 observed falls, comprises 918 stones, 13 irons and 15 stony-irons. A low ratio of falls to finds (represent only $0.01 \%$ of the Moroccan declared meteorites) compared with other countries (e.g., USA $14.3 \%$ ). However the rate of recovery of meteorites (falls + finds) in Morocco exceeds that of most other countries of similar size and range of climatic conditions. More than $95 \%$ of documented meteorites from Morocco have been recovered from Eastern Morocco (Eastern Sahara Moroccan) including many rare types. This Region has proved to be one of the most prolific areas in the world for meteorite finds.
\end{abstract}

Keywords: Meteorites; Find; fall; NWA; chondrites; achondrites; Statistic; Morocco

\section{INTRODUCTION}

As samples from minor planets, meteorites are an unique source of information about a wide variety of events that occurred very early in the history of the solar system and meteorite fall statistics are frequently used by planetary scientists to approximate the true flux of meteorites on the Earth. Well documented meteorites provide the best available measure of the relative abundances of the different types of meteorite that survive their fall to Earth. The aim of statistical studies is to obtain reliable values for the influx of meteorite falls and their mass and the constitution of the meteoritic flux [1].

During the last eighty years, thirteen meteorite falls were recorded in Morocco, which ten are well documented and named Douar Mghila, Oued el Hadjar, Itqiy, Zag, Bensour, Oum Dreyga, Benguerir, Tamdakht, Tissint and Aoussred. It represent only $0.011 \%$ of the Moroccan declared meteorites. The authenticated observed falls represent three types of different meteorites, eight ordinary chondrites, one carbonaceous chondrite and one Shergottite basaltic achondrites. The Morocco meteorite fall recovery rate, during the past eighty years, is low 0.11 falls per year on average per $2.11 \mathrm{~km}^{2}$ [2]. 


\section{MOROCCAN METEORITES}

\section{1. Meteorite falls}

Ten observed falls have been recovered in Morocco. The earliest well-documented meteorite fall occurred in 1932 near Douar Mghila from which hundreds of stones were collected [3]. The most recently recovered fall, a single stone weighing 270 grams, occurred on 20 May, 2012 at Aoussred in Morocco western Sahar [4]. The Morocco meteorite fall recovery rate, during the past 80 years, is low 0.11 falls per year on average (or approximately one fall recovery per 10 year time interval, or equivalently, 0.1 fall per year per $2.11 \mathrm{~km} 2$ ) [2]. All those objects have been watched by eyewitnesses, as it moved in the atmosphere or touched the ground. At the end of May 2012, thirteen official records for observed meteorite falls from Morocco. Moroccan meteors and meteorite falls are listed and their geographical distribution is shown in Figure 1.

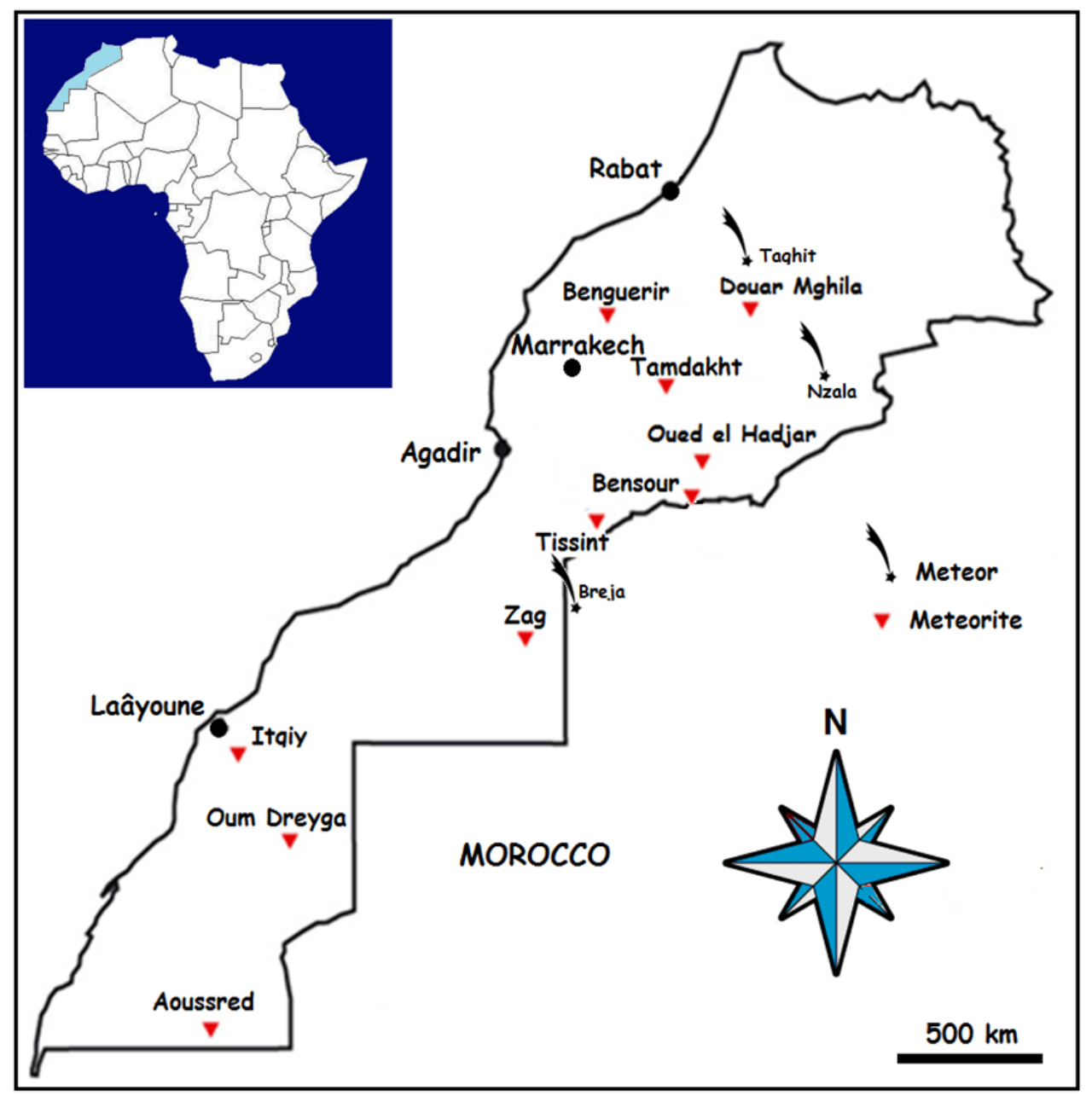

Fig. 1. Map showing the distribution of meteorite falls from Morocco.

The falls of Taghit, Breja, Nzala and Taouz (Fig. 1) by opposition to the other witnessed falls, raises a problem in the exactness of the statements which relate to it. In spite of eyewitnesses' presence, it always misses in the declaration of this fall the essential elements as the exact coordinates and even the precise day of the fall. 


\section{2. Meteorite finds}

More than $50 \%$ of the Morocco comprises deserts or semi-arid land providing conditions for the prolonged preservation of meteorites [5]. The recorded number of distinct meteorites (277) from Morocco, more than $90 \%$ of which have been found in the arid zone, is probably only a small fraction of those available for collection. Also, nearly all meteorites found in deserts fell long before humans actively sought them.

The meteorite finds in Morocco is divided into two groups: (i) All finds whose origin is not set correctly are classified in all meteorites NWA (North West Africa) that can come from Algeria, Libya, Mali, Niger, Nigeria, Mauritania, etc. (ii) The meteorites collected by scientists with GPS data, these meteorites are the name of the locality approved by the Meteorite Nomenclature Committee of the Meteoritical Society.

The geographical distribution this second group is shown in Figure 2. The distribution of meteorite recoveries is generally concentrated in the desert east of Morocco (next to the border with Algeria). Few meteorites have been recorded around centers of population, or in areas of intense agricultural.

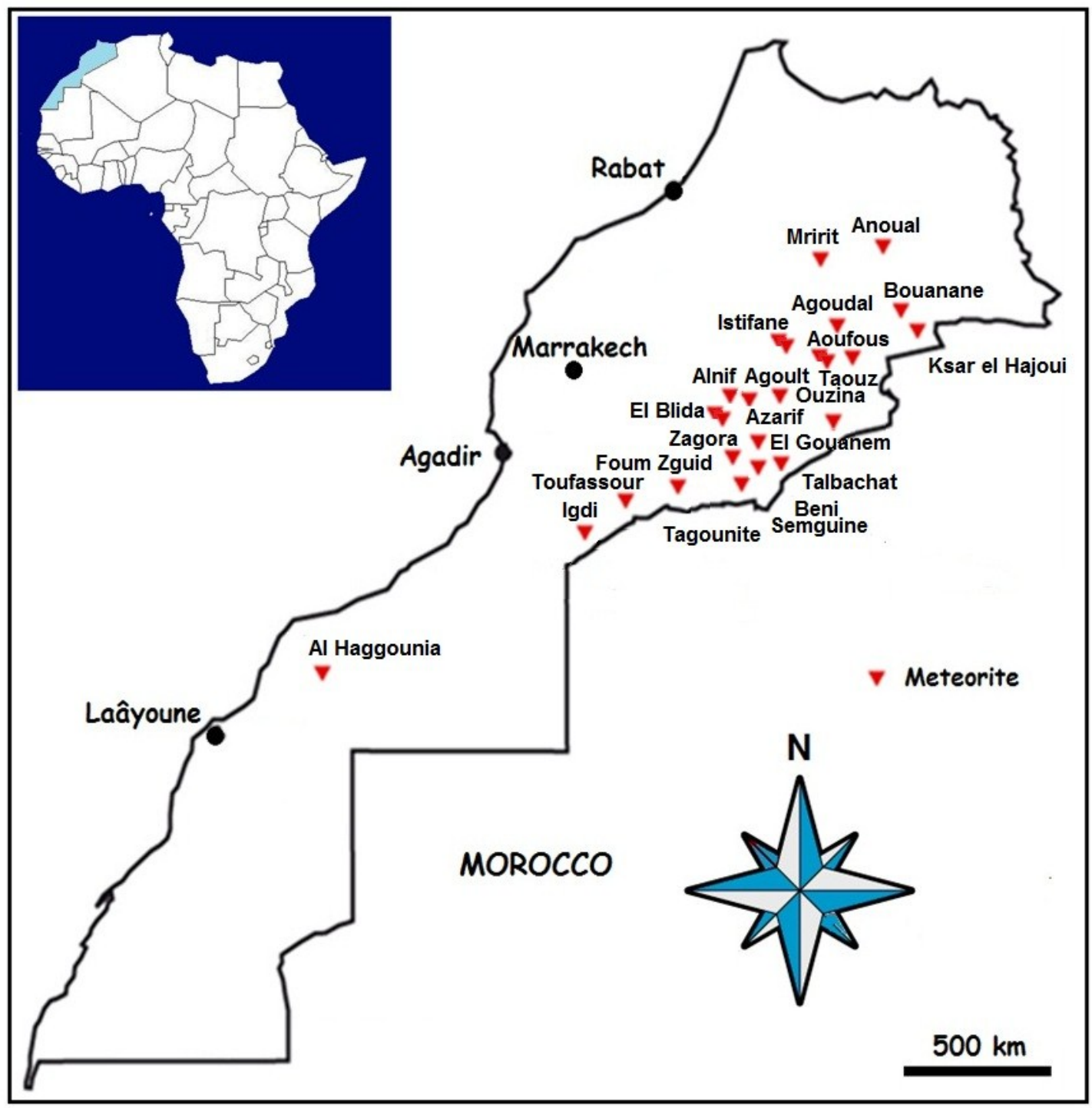

Fig. 2. Map showing the distribution of meteorite collected by scientists from Morocco 
The earliest well-documented recoverie of meteorites in Morocco were large masse of iron weighing $79.9 \mathrm{~kg}$ found in 1937 near the Mrirt village $(25 \mathrm{~km}$ north-east of Khenifra, Morocco) [6]. An even earlier discovery may have been the Douar Mghila stony meteorite, reported to have been found in 1932 in Douar Mghila region, 4 km Est de Béni Mella [3]. The description of this meteorite by Lacroix effectively marked the beginning of research on Moroccan meteorites.

The largest meteorite recovery is an $100 \mathrm{~kg}$ mass of the Bou Azarif H5 found in 2010 on the Zagora plain in Est Moroccan (Meteoritical Bulletin, $\mathrm{N}^{\circ} 100$, MAPS 46, in preparation). $75 \mathrm{~kg}$ de mésosidérite ont été récupérées autour d'un petit cratère d'impact dans la région de Toufassour $[7,8]$.

\section{DISCUSSION AND STATISTICS}

Many rare and some hitherto unknown, types of meteorite have been recovered from Morocco and research on these has played an important role in extending our understanding of the early Solar System. Of these, the fall of more than $20 \mathrm{~kg}$ of stones at Tissint in Tata region on July18, 2011 is probably the most significant. Notably, analysis of Tissint confirmed the existence of extra-terrestrial organic compounds [9].

The abundance of material from the Tissint fall allowed extensive research that has been summarized by Ibhi [10]. Analysis of Tissint confirmed the existence the refractory trace element, sulfur, and fluorine data for the matrix and glass veins in the meteorite indicate the presence of a Martian surface component. Thus, the influence of in situ Martian weathering can be unambiguously distinguished from terrestrial contamination in this meteorite [11].

One of the most remarkable meteorites known is the Northwest Africa (NWA) 7325 meteorite found in 2012 in Western Moroccan Sahara [12]. NWA 7325 has several curious characteristics. The magnetism, the low iron content and the high magnesium content all suggest that Mercury is the meteorite's original home. But other scientists aren't nearly as confident.

The third meteorite, known as NWA 7034, nicknamed "Black Beauty," is the secondoldest of 110 named stones originating from Mars that have been retrieved on Earth. Purchased from a Moroccan meteorite dealer in 2011 is 2.1 billon years old, meaning it formed during what is known as the early Amazonian era in Mars' geologic history. It was Martian and that it was different from all the other ones. The meteorite is relatively rich in water, about 6.000 parts per million, compared with typical Martian meteorites that contain about 200 to 300 parts per million [13].

The significance, if any, of this concentration of rare meteorite types has yet to be investigated, but may be related to the time-span of the population of meteorites sampled in Moroccan desert.

Figure 3 shows the total numbers of meteorites known from Morocco at various times during the period 1932 to 2012. Save for a period of stagnation in the years 1932 to 1994, but uniform growth in the number of recoveries for the period 1997 to 2008 averaging 45 new meteorites per year.

There is also the large increase in the number (255) of recoveries (notably stony meteorites) between 2009 and 2012. The majority of these new meteorites were found in the Zogora, Errachidia and Erfoud Regions of Eastern Morocco. 


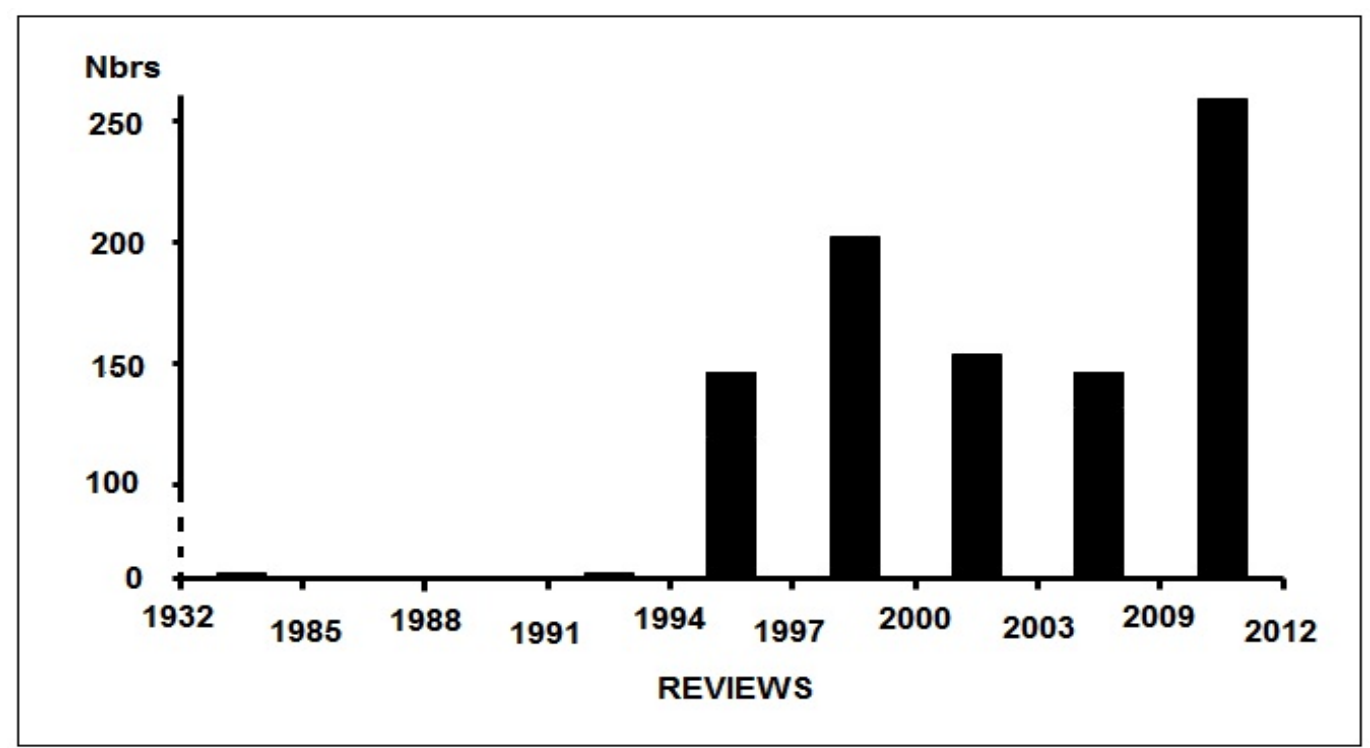

Fig. 3. Meteorites known from Morocco during the period 1932-2012.

The statistics of meteorite falls and finds are presented in Figure 4 and Table. All meteorites that fall on Morocco are stony meteorites with a mass of $406.6 \mathrm{~kg}$. There have been a total of 10 meteorite falls in the time interval 1932 to 2012 . It represent only $0.011 \%$ of the Moroccan declared meteorites. The authenticated observed falls comprise eight ordinary chondrites (Four of type LL, three of type $\mathrm{H}$ and one of type EH), one carbonaceous chondrite and one Shergottite basaltic achondrite. The meteorite finds in Morocco have been a total of 936 meteorite with a total mass of $1,656.6 \mathrm{~kg}$, although only $1.39 \%$ of meteorites are irons and $1.60 \%$ of the stony-iron. Figure 4 shows the number of different types of meteorites collected in Morocco, this list includes only those meteorites that have been approved by the Meteorite Nomenclature Committee of the Meteoritical Society.

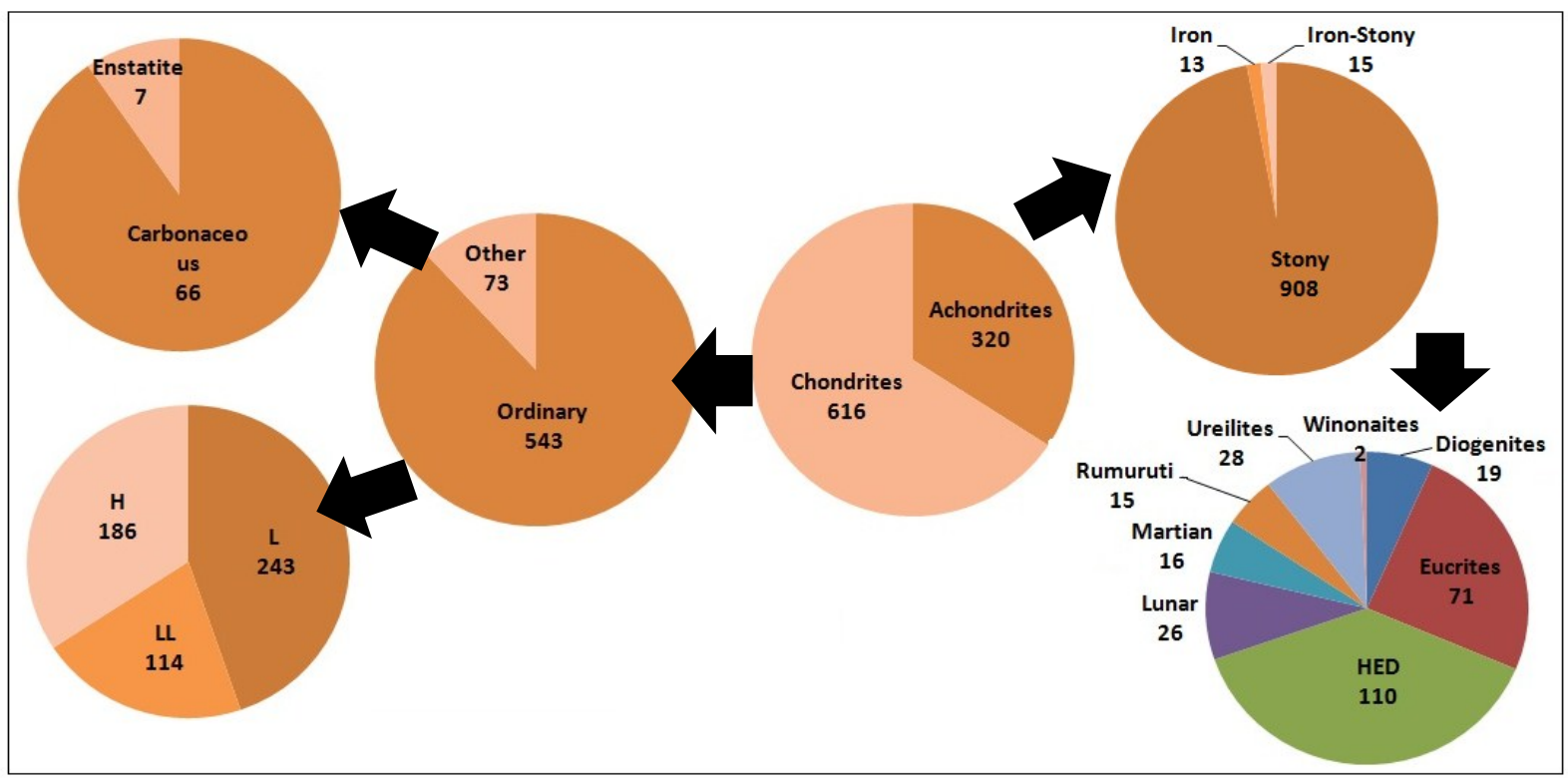

Fig. 4. Moroccan meteorite finds Statistic. 
Table 1. Moroccan meteorite Statistics (Based on all known meteorites)

\begin{tabular}{|c|c|c|c|c|}
\hline Type & Fall \% & Find \% & Fall Weight (kg) & Find Weight $(\mathrm{kg})$ \\
\hline Stony & 100 & 97.01 & 406.60 & $1,242.45$ \\
\hline Stony-Iron & 0 & 1.60 & 0 & 85.30 \\
\hline Iron & 0 & 1.39 & 0 & 328.85 \\
\hline
\end{tabular}

\section{CONCLUSION}

Morocco occupies an important position in the field of meteorites. Moreover, many meteorites collected on its soil, mainly in the southern provinces, some of them are very important source of scientific revelations such as recent Martian meteorites Tissint or NWA 7325 that could be the first known meteorite from the planet Mercury. To date, a total of 946 (328 achondrites and 618 chondrites) authenticated and distinct meteorites have been recorded. The material comprises 918 stones, 13 irons and 15 stony-irons. Collectively, the chondritic meteorites (particularly the ordinary chondrites) are the most abundant types, accounting for $100 \%$ of observed falls and $97.01 \%$ of found meteorites. Irons and stonyirons are the rarest types, accounting for $1.39 \%$ and $1.60 \%$ of the population, respectively. Little bit Moroccan meteorites that remain in the country are held in a few institutional collections. The largest collection of Morocco meteorites is held by the Department of Geology in Ibn Zohr University.

A low ratio of falls to finds (represent only $0.01 \%$ of the Moroccan declared meteorites) compared with other countries (e.g., USA $14.3 \%$ and Australia $5.0 \%$ ). However the rate of recovery of meteorites (falls + finds) in Morocco exceeds that of most other countries of similar size and range of climatic conditions. There have been a total of 10 meteorite falls in the time interval 1932 to 2012. The Morocco meteorite fall recovery rate, during the past 80 years, is low 0.11 falls per year on average (or approximately one fall recovery per 10 year time interval, or equivalently, 0.1 fall per year per $2.11 \mathrm{~km}^{2}$ ). The reasons why so few meteorite falls are recovered per year are no-doubt many and complex. Rasmussen [14] has discussed a number of the possible reasons why the meteorite recovery rate and the documentation of fireball observations Worldwide (have varied with time). A short list of possible factors includes the non-uniform distribution of people, the required development of a scholarly community interested in investigating falls and wars. The list is not quite endless, but it could certainly go on to include geographical conditions in the fall area and weather factors [15]. 


\section{References}

[1] Bevan A. W. R., Australian Meteorites. Records of the Australian Museum Supplement 15. (1992) 1-27.

[2] Ibhi A., International Letters of Chemistry, Physics and Astronomy 12 (2013) 28-35.

[3] Lacroix M. A., Comptes rendus hebdomadaires des séances de l'Académie des Sciences 197 (1933) 368-369.

[4] Ait Kadi M., Bulletin d'Information de l'Académie Hassan II des Sciences et Techniques 12 (2012) 106-108.

[5] Ibhi A., Nachit H., Abia El. H., Ait Touchnt A., Vaccaro C., International Journal of Astronomy and Astrophysics 3(2A) (2013) 1-4.

[6] Hey M. H., Meteoritical Bulletin 40. Meteoritics 5 (1967) 85-109.

[7] Ibhi A., Nachit H., Abia E. H., Meteorite 16(1) (2010) 15-18.

[8] Ibhi A. and Darbali M., 3th Planetary Crater Consortium Meeting, USA, 2011 Abstract No. 1102 .

[9] Wallis J., Wickramasinghe C., Wallis D., Miyake N., Wallis M., Di Gregorio B., Al Mufti S., J. Cosmology 18 (2012) 8500-8505.

[10] Ibhi A., International Letters of Chemistry, Physics and Astronomy 11 (2013) 20-25.

[11] Aoudjehane H.C. et al., Science 3386108 (2013) 785-788.

[12] Witze A., Science News 183 (2013) 5-6.

[13] Agee C.B. et al., Science 3396121 (2013) 780-785.

[14] Rasmussen, K. L., Quarterly Journal of the Royal Astronomical Society 31 (1991) 95108.

[15] Beech M., Journal of the Royal Astronomical Society of Canada 97 (2003) 71-77. 